\title{
Research on Energy-Saving Design of Overhead Travelling Crane Camber Based on Probability Load Distribution
}

\author{
Tong Yifei, ${ }^{1}$ Tang Zhaohui,, ${ }^{1}$ Mei Song, ${ }^{2}$ Shen Guomin,, ${ }^{1}$ and Gu Feng ${ }^{3}$ \\ ${ }^{1}$ School of Mechanical Engineering, Nanjing University of Science and Technology, Nanjing 210094, China \\ ${ }^{2}$ Nanjing Research Institute for Agricultural Mechanization, Ministry of Agriculture, Nanjing 210014, China \\ ${ }^{3}$ Nantong Vocational University, Nantong 226007, China \\ Correspondence should be addressed to Tong Yifei; tyf51129@aliyun.com
}

Received 20 November 2013; Revised 11 March 2014; Accepted 14 March 2014; Published 16 April 2014

Academic Editor: Massimo Scalia

Copyright (C) 2014 Tong Yifei et al. This is an open access article distributed under the Creative Commons Attribution License, which permits unrestricted use, distribution, and reproduction in any medium, provided the original work is properly cited.

\begin{abstract}
Crane is a mechanical device, used widely to move materials in modern production. It is reported that the energy consumptions of China are at least 5-8 times of other developing countries. Thus, energy consumption becomes an unavoidable topic. There are several reasons influencing the energy loss, and the camber of the girder is the one not to be neglected. In this paper, the problem of the deflections induced by the moving payload in the girder of overhead travelling crane is examined. The evaluation of a camber giving a counterdeflection of the girder is proposed in order to get minimum energy consumptions for trolley to move along a nonstraight support. To this aim, probabilistic payload distributions are considered instead of fixed or rated loads involved in other researches. Taking 50/10 t bridge crane as a research object, the probability loads are determined by analysis of load distribution density functions. According to load distribution, camber design under different probability loads is discussed in detail as well as energy consumptions distribution. The research results provide the design reference of reasonable camber to obtain the least energy consumption for climbing corresponding to different $P_{0}$; thus energy-saving design can be achieved.
\end{abstract}

\section{Introduction}

Crane is a mechanical device, used to move widely materials in modern production. It plays a very important role in the national economy with greatly reduced labour intensity, improved production efficiency, and promoted social development as an indispensable auxiliary tool and process equipment [1]. Therefore, its energy consumption becomes an unavoidable topic and, in fact, energy consumption of crane is very huge [2]. There are several reasons influencing the energy loss, and the camber of the girder is the one not to be neglected [3]. When overhead travelling crane works, wheels of the trolley will press on the bridge and generate downward bend. If the deformation is too large, the phenomena of "climbing" will occur and the driving force required will increase [4]. Meanwhile, the deformation can affect the performance of crane trolley badly. The camber of girder can decrease the running resistance and ensure the crane to be safe and steady when running. Thus, it is necessary to design the camber for crane girder so as to compensate the deformation of girder by its weight and loading, which can decrease the deformation affections and energy loss, enhance the bearing capacity of crane, reduce crane climbing and slip slope, and ensure smooth running.

At present, camber curve of crane girder plate is widely adopted [5], while welding, self-weight, and the loading can cause deformation, so it is difficult to obtain an ideal camber curve. Rongbo discussed the basic principles of camber curve on the girder and introduced the camber specified by domestic and international technical standards. Furthermore, various forms of special prechange curve were proposed [6]. In literature [7], the advantages and disadvantages of popular camber curve (parabola, sinusoidal, and threefold) were discussed and a new camber was proposed. However, the above researches about camber are generally based on rated load. In fact, during the actual operation, the crane hoist/load is random varying from empty load to rated load. Under light load, climbing or downgrading of trolley is 
unavoidable with different energy consumptions corresponding to different loadings. Also, camber under rated load may not be the most energy-saving. As for cranes often with heavy loadings, the precamber of girder needs to be larger and for cranes often with light loadings smaller. Thus, operation under nonrated load will result in climbing and slip-on as well as increased energy loss. Professor Gao and Master Tian tested eight in-service representative bridge cranes to collect operation data (load, trolley position, working hours, etc.) and proposed the standard of hoisting load spectrum [8]. But the research was not continued deeply for energy-saving camber design. Therefore, research on camber design of crane is of great importance to accurately determine the camber curve of crane girder plate, control the girder camber, and reduce crane energy consumptions as well as to ensure crane safety. To this aim, probabilistic payload distributions are considered instead of fixed or rated loads involved in other researches.

The present work was carried out in order to seek reasonable camber to obtain the least energy consumption corresponding to different probability loads. In Section 2, load spectrum of crane is studied based on analysis of load status level and corresponding load spectrum coefficient. In Section 3, taking 50/10 t bridge crane as research object, the probability loads are determined by analysis of load distribution density functions. In Section 4, camber design for different probability loads is discussed in detail as well as energy consumptions distribution. Finally, research conclusions are summarized.

\section{Probability Load Analysis of Crane}

Precamber is generally determined according to rated load, while the loading at work is uncertain, varying from empty load to rated load. By analyzing the load spectrum of crane to master the crane's work conditions, corresponding camber can be determined.

2.1. Load Spectrum Coefficient. The lifting weight of crane is uncertain, varying from 0 to rated load or even overweight. Therefore, uncertain load parameters should be adopted for analysis with considerations of the camber. Load spectrum coefficient describes the randomness of crane loading and can reflect the laws of loadings statistically as well as the loading status from the view of loading changes and use frequency of each typical load. In GB/T 3811, load spectrum coefficient is defined for calculation as [9]

$$
K_{P}=\sum\left[\frac{C_{i}}{C_{T}}\left(\frac{P_{Q_{i}}}{P_{\mathrm{Q} \max }}\right)^{m}\right],
$$

where

$K_{P}$ is the load spectrum coefficient;

$C_{i}$ is the number of cranes working cycles corresponding to each typical load;

$C_{T}$ is the total number of cranes working cycles;

$P_{\mathrm{Q}_{i}}$ is the typical lifting load within expected lifetime of the cranes;
TABLE 1: Load status level and corresponding load spectrum coefficient.

\begin{tabular}{lcl}
\hline $\begin{array}{l}\text { Load status } \\
\text { levels }\end{array}$ & $\begin{array}{c}\text { Load spectrum } \\
\text { coefficient of crane, } K_{p}\end{array}$ & Work conditions \\
\hline Q1 & $K_{p} \leq 0.125$ & $\begin{array}{l}\text { Seldom for rated load } \\
\text { and often light load }\end{array}$ \\
Q2 & $0.125<K_{p} \leq 0.250$ & $\begin{array}{l}\text { Seldom for rated load } \\
\text { and often medium load }\end{array}$ \\
Q3 & $0.250<K_{p} \leq 0.500$ & $\begin{array}{l}\text { Sometimes for rated load } \\
\text { and often heavy load }\end{array}$ \\
Q4 & $0.500<K_{p} \leq 1.000$ & Often for rated load \\
\hline
\end{tabular}

$P_{\mathrm{Qmax}}$ is the rated load;

$m$ is the exponent for facilitating the level division $(m=3)$.

Currently load status can usually be divided into four levels based on load spectrum coefficient, as shown in Table 1.

2.2. Crane Hoisting Load Spectrum. It is reported in literature [8] that eight in-service overhead traveling cranes are monitored and tested for collecting operation data. Statistical analysis results of the collected data show that the loading of overhead traveling crane passes the normality test at the significant level of 0.05 , suggesting that the load is normally distributed. Thus, load belonging to different load status levels will generate different normal distribution density functions as follows:

$$
f_{\bar{x}_{t}, \bar{s}_{t}^{2}(x)}=\frac{1}{\bar{s}_{t} \sqrt{2 \pi}} e^{-\left(x-\bar{x}_{t}\right)^{2} / 2 \bar{s}_{t}^{2}} .
$$

From formula (2), it can be seen that there are load mean $\left(\bar{x}_{t}\right)$ and standard deviation $\left(\bar{s}_{t}\right)$ which are two key parameters, which is closely related with rated hoisting load denoted by " $\bar{x}_{t}=\mu_{\mathrm{Q}} x_{t \max }$ " and ' $\bar{s}_{t}=\sigma_{\mathrm{Q}} x_{t \max }$ "' where $x_{t \max }$ denotes rated hoisting weight/load and $\mu_{\mathrm{Q}}, \sigma_{\mathrm{Q}}$ denote the mean and standard deviation of hoisting weight/load, respectively.

So, it is necessary to get $\mu_{Q}, \sigma_{Q}$ for obtaining load mean $\left(\bar{x}_{t}\right)$ and standard deviation $\left(\bar{s}_{t}\right)$. Some practical data of cranes are collected in order to fit the normal distribution and solute $\mu_{\mathrm{Q}}$ and $\sigma_{\mathrm{Q}} \cdot P_{\mathrm{Q}_{i}}, P_{\mathrm{Q} \max }, C_{i}$, and $C_{T}$ are recorded. $\mu_{\mathrm{Q}}$ can be calculated by the summation of the product of loading value multiplied by probability of loading, while the probability of loading can be approximately calculated by $C_{i} / C_{T}$, which means the portion of the number of cranes working cycles under each typical load to the total number of cranes working cycles. So,

$$
\begin{gathered}
\mu_{\mathrm{Q}}=\sum\left[\frac{C_{i}}{C_{T}}\left(\frac{P_{\mathrm{Q}_{i}}}{P_{\mathrm{Q} \max }}\right)\right] \\
\sigma_{\mathrm{Q}}=\sqrt{\sum \frac{C_{i}}{C_{T}}\left(\frac{P_{\mathrm{Q}_{i}}}{P_{\mathrm{Q} \max }}-\mu_{\mathrm{Q}}\right)^{2}} .
\end{gathered}
$$


Let $\delta_{\mathrm{Q}}$ denote the variation coefficient, and

$$
\delta_{\mathrm{Q}}=\frac{\sigma_{\mathrm{Q}}}{\mu_{\mathrm{Q}}} .
$$

The hoisting/load spectrum of overhead crane can reflect the hoisting/load probability distribution under certain status level, which provide data supports for further research on the camber under different loadings.

On the other hand, the running track of trolley is also random, varying from middle to both ends or from end to middle or around the middle. In practice, the trolley generally goes through the middle of the girder. So for calculation simplification, the operation of trolley per work cycle is regarded as one climbing.

\section{Probability Load Determination of Crane}

Box overhead crane is a typical overhead travelling widely used at home and abroad with simple design, good manufacturing processes, structural stability, and other advantages. Take a 50/10 t overhead crane used in a practical project as the research object (shown in Figure 1).

Parameters of the research object are as follows:

(i) rated load is $50 \mathrm{t}$;

(ii) effective length of the girder is $31.5 \mathrm{~m}$;

(iii) gauge of trolley is $3580 \mathrm{~mm}$;

(iv) weight of total girder is $37.8 \mathrm{t}$ (beam: $14.833 \mathrm{t}$ and end girder: $4.067 \mathrm{t}$ );

(v) weight of trolley is $15.4 \mathrm{t}$;

(vi) $H$, the spacing between top and bottom plate, is $1700 \mathrm{~mm}$;

(vii) $B_{1}$, width of the plate, is $650 \mathrm{~mm}$;

(viii) $B_{2}$, the spacing between webs, is $590 \mathrm{~mm}$;

(ix) $T_{11} / T_{12}$, the thickness of top/bottom plate, is $24 \mathrm{~mm}$;

(x) $T_{21} / T_{22}$, the thickness of left/right web, is $6 \mathrm{~mm}$;

(xi) the spacing between big stiffening ribs is $1200 \mathrm{~mm}$ $2750 \mathrm{~mm}$;

(xii) the spacing between small stiffening ribs is $400 \mathrm{~mm} \sim 550 \mathrm{~mm}$;

(xiii) material is ordinary carbon steel Q235.
The rated load is $50 \mathrm{t}$; that is, $x_{t \max }=500 \mathrm{KN}$ and the parameters of $\bar{x}_{t}, \bar{s}$, and confidence level corresponding to the above four work conditions are as follows:

$$
\begin{gathered}
\text { Q1: } \bar{x}_{t}=\mu_{\mathrm{Q}} x_{t \max }=229 \mathrm{KN}, \quad \bar{s}_{t}=\sigma_{\mathrm{Q}} x_{t \max }=73 \mathrm{KN}, \\
U_{1}=\int_{0}^{500} \frac{1}{\bar{s}_{t} \sqrt{2 \pi}} e^{-\left(P-\bar{x}_{t}\right)^{2} / 2 \bar{s}_{t}^{2}} d P=0.99904 \\
\text { Q2: } \bar{x}_{t}=a x_{t \max }=304.5 \mathrm{KN}, \quad \bar{s}_{t}=b x_{t \max }=56 \mathrm{KN}, \\
U_{2}=\int_{0}^{500} \frac{1}{\bar{s}_{t} \sqrt{2 \pi}} e^{-\left(P-\bar{x}_{t}\right)^{2} / 2 \bar{s}_{t}^{2}} d P=0.9999 \\
\text { Q3: } \bar{x}_{t}=a x_{t \max }=394 \mathrm{KN}, \quad \bar{s}_{t}=b x_{t \max }=34.5 \mathrm{KN}, \\
U_{3}=\int_{0}^{500} \frac{1}{\bar{s}_{t} \sqrt{2 \pi}} e^{-\left(P-\bar{x}_{t}\right)^{2} / 2 \bar{s}_{t}^{2}} d P=0.998939 \\
\text { Q4: } \bar{x}_{t}=a x_{t \max }=450 \mathrm{KN}, \quad \bar{s}_{t}=b x_{t \max }=20 \mathrm{KN}, \\
U_{4}=\int_{0}^{500} \frac{1}{\bar{s}_{t} \sqrt{2 \pi}} e^{-\left(P-\bar{x}_{t}\right)^{2} / 2 \bar{s}_{t}^{2}} d P=0.99379 .
\end{gathered}
$$

As the crane load is impossible to be negative and cannot exceed the rated load, so all loads should occur within the interval $\left[0, P_{\max }\right]$, the range of whose normal distribution function is $(-\infty,+\infty)$. According to the checking by the above formulas, it can be found that the probability of loads appearing in $\left[0, P_{\max }\right]$ is greater than 0.99 . So $\left[0, P_{\max }\right]$ can be replaced by $(-\infty,+\infty)$ and the load distribution density functions, corresponding to $Q 1, Q 2, Q 3$, and $Q 4$, can be expressed as

$$
\begin{aligned}
& \text { Q1: } f_{\bar{x}_{t}, \bar{s}_{t}^{2}(P)}=\frac{1}{\bar{s}_{t} \sqrt{2 \pi}} e^{-\left(P-\bar{x}_{t}\right)^{2} / 2 \bar{s}_{t}^{2}} \\
& =\frac{1}{73 \sqrt{2 \pi}} e^{-(P-229)^{2} / 2 \times 73^{2}} \\
& =0.00546 e^{-(P-229)^{2} / 10658} \\
& \text { Q2: } f_{\bar{x}_{t}, \bar{s}_{t}^{2}(P)}=\frac{1}{\bar{s}_{t} \sqrt{2 \pi}} e^{-\left(P-\bar{x}_{t}\right)^{2} / 2 \bar{s}_{t}{ }^{2}} \\
& =\frac{1}{56 \sqrt{2 \pi}} e^{-(P-304.5)^{2} / 2 \times 56^{2}} \\
& =0.00712 e^{-(P-304.5)^{2} / 6272} \\
& \text { Q3: } f_{\bar{x}_{t}, \bar{s}_{t}^{2}(P)}=\frac{1}{\bar{s}_{t} \sqrt{2 \pi}} e^{-\left(P-\bar{x}_{t}\right)^{2} / 2 \bar{s}_{t}^{2}} \\
& =\frac{1}{34.5 \sqrt{2 \pi}} e^{-(P-394)^{2} / 2 \times 34.5^{2}}
\end{aligned}
$$




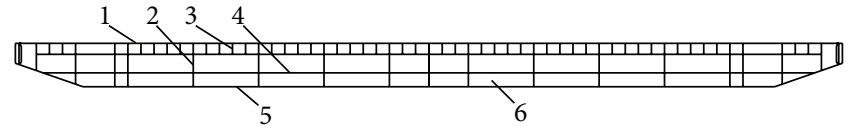
(1) Top plate
(2) Big stiffening ribs
(3) Small stiffening ribs
(4) Horizontal angle iron
(5) Bottom plate
(6) Webs

(a) Structural illustration of girder

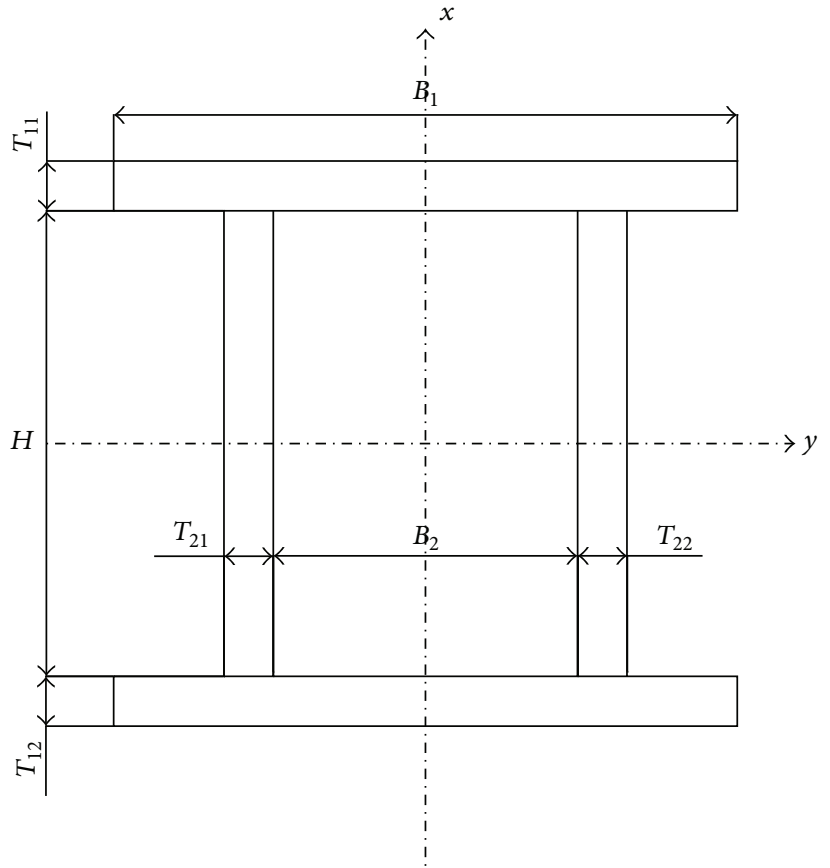

(b) Section attributes illustration

Figure 1: Model of 50/10 t overhead crane.

$$
\text { Q4: } \begin{aligned}
f_{\bar{x}_{t}, \bar{s}_{t}{ }^{2}(P)} & =\frac{1}{\bar{s}_{t} \sqrt{2 \pi}} e^{-\left(P-\bar{x}_{t}\right)^{2} / 2 \bar{s}_{t}^{2}} \\
& =\frac{1}{20 \sqrt{2 \pi}} e^{-(P-450)^{2} / 2 \times 20^{2}} \\
& =0.01994 e^{-(P-450)^{2} / 800}
\end{aligned}
$$

The distribution function curves are shown in Figure 2.

From Figure 2, it can be concluded that, with the load status level improved, the hoisting/load mean gradually increases and the load distribution becomes more concentrated. The loads of $Q 4$ are distributed around the rated load with a certain probability of overloading.

Actually, some operation parameters of cranes cannot be obtained for crane design. If the load spectrum of overhead crane is not available, the load distribution cannot be obtained according to Table 2. But generally the load is considered as conformed to normal distribution $\left[0, P_{\max }\right]$. Then according to design handbook of cranes, $\mu_{\mathrm{Q}}$ and $\sigma_{\mathrm{Q}}$ for hook hoisting of overhead crane can be basically determined. Generally $\mu_{\mathrm{Q}} \in(0.5-0.6)$ and $\sigma_{\mathrm{Q}} \in(0.15-0.2)$. Due to different work conditions of different cranes with different loadings, the values of $\mu_{\mathrm{Q}}$ and $\sigma_{\mathrm{Q}}$ are different. Here, let $\mu_{\mathrm{Q}}=0.55$ and $\sigma_{\mathrm{Q}}=0.18$ by design experts. Then according to $\bar{x}_{t}=$ $\mu_{\mathrm{Q}} x_{t \max }, \bar{s}_{t}=\sigma_{\mathrm{Q}} x_{t \max }$, and $x_{t \max }=500 \mathrm{KN}, \bar{x}_{t}=275 \mathrm{KN}$, $\bar{s}_{t}=90 \mathrm{KN}$.

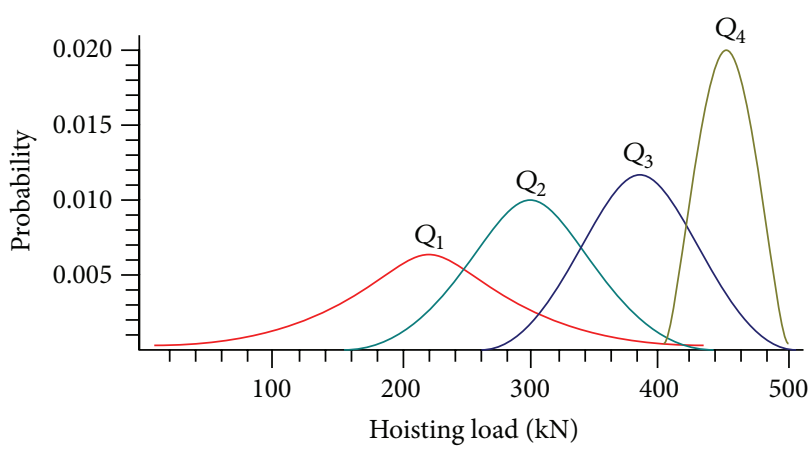

FIGURE 2: Distribution function curve corresponding to Q1, Q2, Q3, and Q4.

Placing obtained $\bar{x}_{t}$ and $\bar{s}$ into formula (2), the density function of load distribution can be obtained as

$$
\begin{aligned}
f_{\bar{x}_{t}, \bar{s}_{t}^{2}(P)} & =\frac{1}{\bar{s}_{t} \sqrt{2 \pi}} e^{-\left(P-\bar{x}_{t}\right)^{2} / 2 \bar{s}_{t}^{2}} \\
& =\frac{1}{90 \sqrt{2 \pi}} e^{-(P-275)^{2} / 2 \times 90^{2}} \\
& =0.004434 e^{-(P-275)^{2} / 16200} .
\end{aligned}
$$

The distribution is illustrated as shown in Figure 3 and the probability of loads appearing in $\left[0, P_{\max }\right]$ is 0.992667 . 
TABLE 2: Hanging heavy load spectrum of standard recommended by GB/T 3811 [10].

\begin{tabular}{|c|c|c|c|c|}
\hline Load status levels & Nominal load spectrum coefficient, $K_{p}$ & $M_{\mathrm{Q}}$ & $\sigma_{\mathrm{Q}}$ & Load spectrum coefficient \\
\hline Q1 & $K_{p} \leq 0.125$ & 0.458 & 0.146 & 0.125 \\
\hline Q2 & $0.125<K_{p} \leq 0.250$ & 0.609 & 0.112 & 0.250 \\
\hline Q3 & $0.250<K_{p} \leq 0.500$ & 0.788 & 0.069 & 0.500 \\
\hline Q4 & $0.500<K_{p} \leq 1.000$ & 0.900 & 0.04 & 0.9 \\
\hline
\end{tabular}

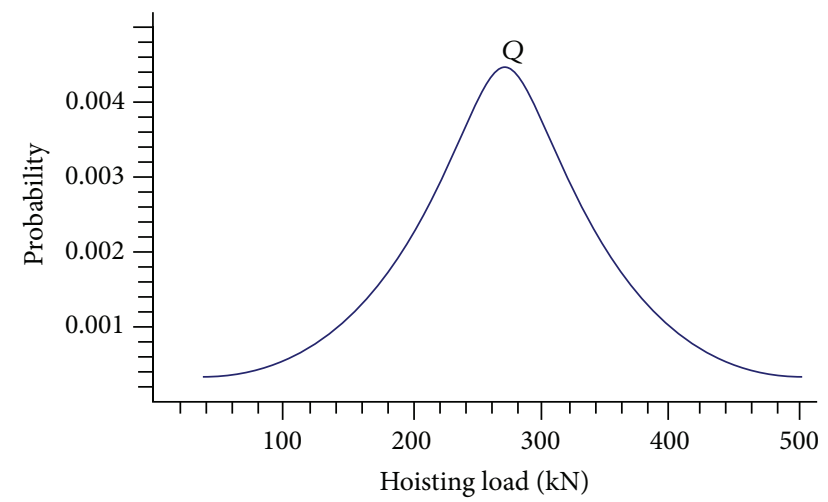

FIGURE 3: Distribution function curve corresponding to uncertain load level.

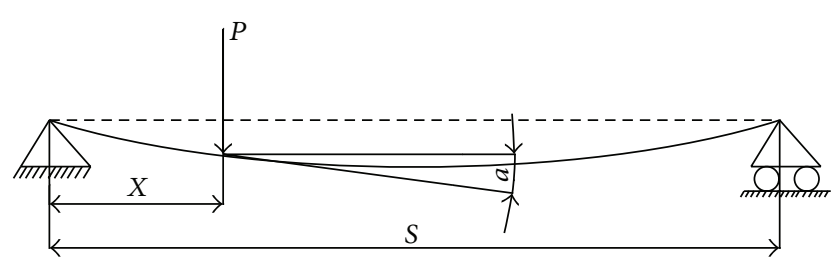

FIGURE 4: Girder illustration under wheel pressure $(P$ denotes the load, $X$ denotes the distance between loading position and left end, $S$ denotes the span length, and $\alpha$ denotes the inclination).

\section{Matching of Camber with Probability Load/Hoisting}

As shown in Figure 4, the bridge crane can be considered as simply supported beam and it is necessary to overcome the climbing resistance when trolley is moving on the bending track. The climbing resistance is closely related to the slope where trolley moves to. To eliminate the climbing resistance, the ideal camber curve should ensure that the slope remains zero $(0)$ for trolley at any position on the girder.

That is,

$$
\alpha_{\text {camber }}+\alpha=0
$$

where $\alpha_{\text {camber }}$ denotes the inclination with prefabricated camber and $\alpha$ denotes the inclination without camber which can make sure the slope remains zero (0) for trolley at any position on the girder.

At certain position $X$, the downwarping inclination $\alpha$ equals: (simply supported beam classic formula)

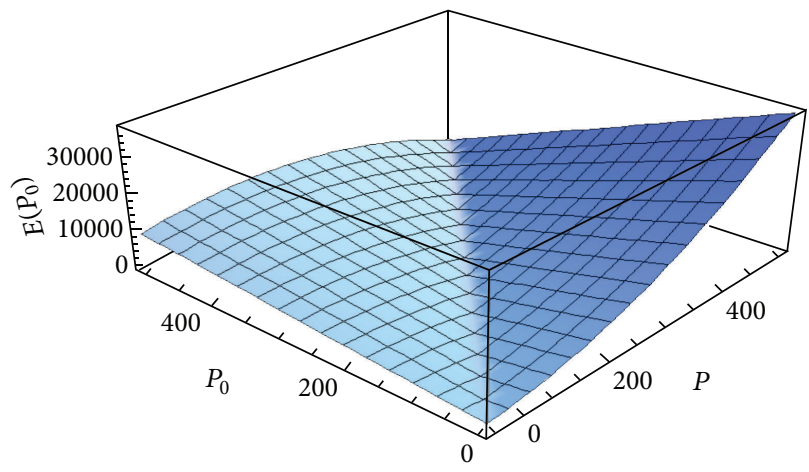

FIGURE 5: Load energy consumptions distribution.

$$
\begin{gathered}
\alpha=-\frac{P S^{2}}{3 E I} \frac{X}{S}\left(1-\frac{X}{S}\right)\left(1-\frac{2 X}{S}\right) \\
\because E=\int(f \times s) d s .
\end{gathered}
$$

Here, $f$ is the sum of $P$ and the weight of trolley and is $(P+157), s$ denotes the vertical displace, and $s=d x \times$ $\tan \alpha$. The energy consumed equals the work done by the vertical load acting on the girder to generate a displacement (downwarping).

So, when the camber designed consumes minimum energy under the load of $P_{0}$, if loading is $P$, then trolley running from the middle of girder to the end position will make useless power work done as much as

$$
E_{P}^{P_{0}}=\int_{0}^{L / 2}(P+157)\left|\operatorname{tg} \alpha_{P_{0}}-\operatorname{tg} \alpha_{P}\right| d x,
$$

where $\alpha_{P_{0}}$ denotes the inclination at certain position $X$ on the prefabricated camber, which is designed to consume minimum energy under load of $P_{0}$.

If $\alpha$ is very small, then $\tan \alpha \approx \alpha$ and the energy consumptions loading probability load $P$ according to the load curve with design load $P_{0}$ and with considerations of the weight of trolley $(157 \mathrm{KN})$ can be expressed as

$$
E_{P}^{P_{0}}=\int_{0}^{L / 2}(P+157)\left|\alpha_{P_{0}}-\alpha_{P}\right| d x
$$

The energy consumptions distribution is shown in Figure 5.

Place formula (9) into formula (11); then

$$
E^{P_{0}}=\int_{0}^{L / 2}(P+157) \frac{S^{2}}{6 E I} \cdot \frac{x}{S}\left(1-\frac{4 x^{2}}{S^{2}}\right)\left|P_{0}-P\right| d x \text {. }
$$


After solution of the differential equations, energy consumptions can be obtained:

$$
E^{P_{0}}=(P+157)\left|P_{0}-P\right| \frac{S^{3}}{48 E I}
$$

Take a 50/10 t overhead crane, for example, and input the value of $S, E$, and $I$; then

$$
E^{P_{0}}=0.11(P+157)\left|P_{0}-P\right|
$$

From Figure 5, it can be found that the minimum energy consumptions occur when $P$ approaches $P_{0}$ and the energy consumptions are less when $P<P_{0}$ than when $P>P_{0}$ because of heavier loading. So, heavier load can be considered for camber design to guarantee less energy consumptions when overloading.

With combinations of each load distribution density function, $E^{P_{0}}$, which denotes the energy consumptions of the crane whose camber is based on $P_{0}$ and under loadings of normal distribution, can be calculated as

$$
E^{P_{0}}=\int_{0}^{P_{\max }} \frac{1}{\bar{s}_{t} \sqrt{2 \pi}} e^{-\left(P-\bar{x}_{t}\right)^{2} / 2 \bar{s}_{t}^{2}}(P+157)\left|P-P_{0}\right| \frac{S^{3}}{48 E I} d P .
$$

Remove the absolute value and expand formula (15); then

$$
\begin{aligned}
E^{P_{0}}= & \frac{1}{\bar{s}_{t} \sqrt{2 \pi}} \frac{S^{3}}{48 E I} \\
& \quad \times\left(\int_{0}^{P_{0}} e^{-\left(P-\bar{x}_{t}\right)^{2} / 2 \bar{s}_{t}^{2}}(P+157)\left(P_{0}-P\right) d P\right. \\
& \left.\quad+\int_{P_{0}}^{P_{\max }} e^{-\left(P-\bar{x}_{t}\right)^{2} / 2 \bar{s}_{t}^{2}}(P+157)\left(P-P_{0}\right) d P\right) .
\end{aligned}
$$

Then, the energy consumptions under Q1, Q2, Q3, and Q4 can be obtained as well as energy consumptions distribution shown in Figures 6-9:

Q1:

$$
\begin{gathered}
E^{P_{0}=} 0.0006 \cdot\left(\int _ { 0 } ^ { P _ { 0 } } e ^ { - ( P - 2 2 9 ) ^ { 2 } / 1 0 6 5 8 } \cdot ( P + 1 5 7 ) \left(P_{0}\right.\right. \\
+\int_{P_{0}}^{500} e^{-(P-229)^{2} / 10658} \\
\left.\cdot(P+157)\left(P-P_{0}\right) d P\right) \\
=-4.17+18.04 e^{\left(0.0430-0.0000938 P_{0}\right) P_{0}} \\
\quad-0.0052 P_{0}+\left(10291.5-42.385 P_{0}\right) \\
\quad \times \operatorname{Erf}\left[2.22-0.00968 P_{0}\right]
\end{gathered}
$$

Q2:

$$
\begin{aligned}
& E^{P_{0}}=0.00078 \cdot\left(\int_{0}^{P_{0}} e^{-(P-304.5)^{2} / 6272}(P+157)\left(P_{0}-P\right) d P\right. \\
& +\int_{P_{0}}^{500} e^{-(P-304.5)^{2} / 6272} \\
& \left.\times(P+157)\left(P-P_{0}\right) d P\right) \\
& =-9.27+0.000896 e^{\left(0.0968-0.000159 P_{0}\right) P_{0}}+0.018 P_{0} \\
& +\left(15752.2-50.60 P_{0}\right) \operatorname{Erf}\left[3.8396-0.0126 P_{0}\right]
\end{aligned}
$$

Q3:

$$
\begin{aligned}
& E^{P_{0}}=0.00127\left(\int_{0}^{P_{0}} e^{-(P-394)^{2} / 2380.5}(P+157)\left(P_{0}-P\right) d P\right. \\
& +\int_{P_{0}}^{500} e^{-(P-394)^{2} / 2380.5} \\
& \left.\times(P+157)\left(P-P_{0}\right) d P\right) \\
& =-40.433+7.54 \times 10^{-26} \widetilde{a}^{\left(0.33-0.00042 P_{0}\right) P_{0}}+0.0793 P_{0} \\
& +\left(23996.77-60.54 P_{0}\right) \operatorname{Erf}\left[8.08-0.020 P_{0}\right]
\end{aligned}
$$

Q4:

$$
\begin{gathered}
E^{P_{0}}=0.00219\left(\int_{0}^{P_{0}} e^{-(P-450)^{2} / 800}(P+157)\left(P_{0}-P\right) d P\right. \\
+\int_{P_{0}}^{500} e^{-(P-450)^{2} / 800}
\end{gathered}
$$




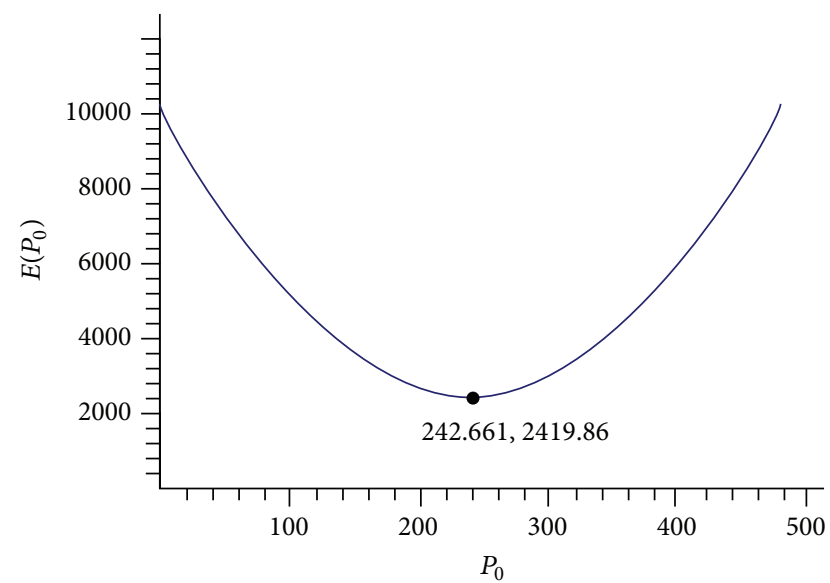

FIGURE 6: Energy consumptions distribution with probability load $P_{0}$ under $Q 1$.

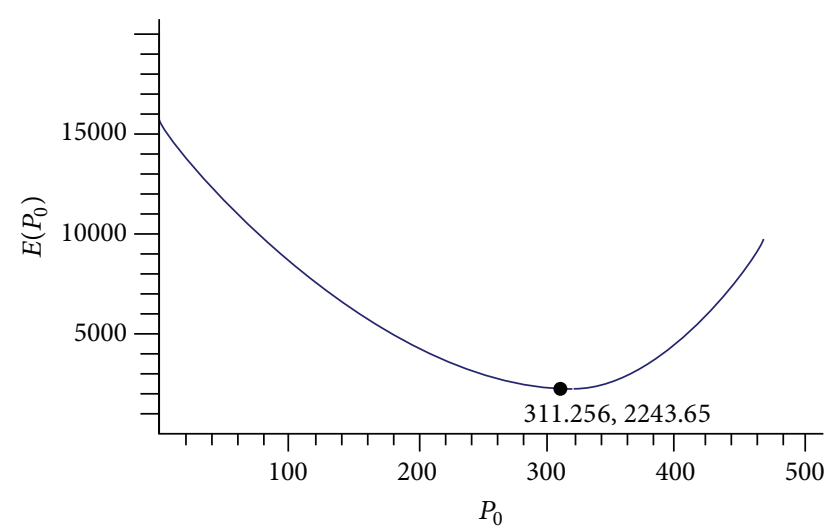

FIGURE 7: Energy consumptions distribution with probability load $P_{0}$ under $Q 2$.

$$
\begin{gathered}
\left.\times(P+157)\left(P-P_{0}\right) d P\right) \\
=-229.103+1.25 \times 10^{-107} e^{\left(1.125-0.00125 P_{0}\right) P_{0}}+0.45 P_{0} \\
+\left(30033.1-66.64 P_{0}\right) \operatorname{Erf}\left[15.91-0.035 P_{0}\right] .
\end{gathered}
$$

From Figure 6, it can be found that when $c=0$, that is, without camber, energy consumptions are greatly increased. With $P_{0}$ acting on the girder and increasing, $E^{P_{0}}$ decreases. When $P_{0}$ approaches $242.661 \mathrm{KN}$, the minimum of $E^{P_{0}}$ occurs as $2419.86 \mathrm{~J}$. If $P_{0}$ continues to increase, $E^{P_{0}}$ will increase.

Similarly from Figure 7, it can be found that, when $P_{0}$ approaches $311.256 \mathrm{KN}$, the minimum of $E^{P_{0}}$ occurs as $2243.65 \mathrm{~J}$.

Similarly from Figure 8, it can be found that, when $P_{0}$ approaches $396.3 \mathrm{KN}$, the minimum of $E^{P_{0}}$ occurs as 1654.47 J.

Similarly from Figure 9, it can be found that, when $P_{0}$ approaches $450.489 \mathrm{KN}$, the minimum of $E^{P_{0}}$ occurs as $1037.59 \mathrm{~J}$.

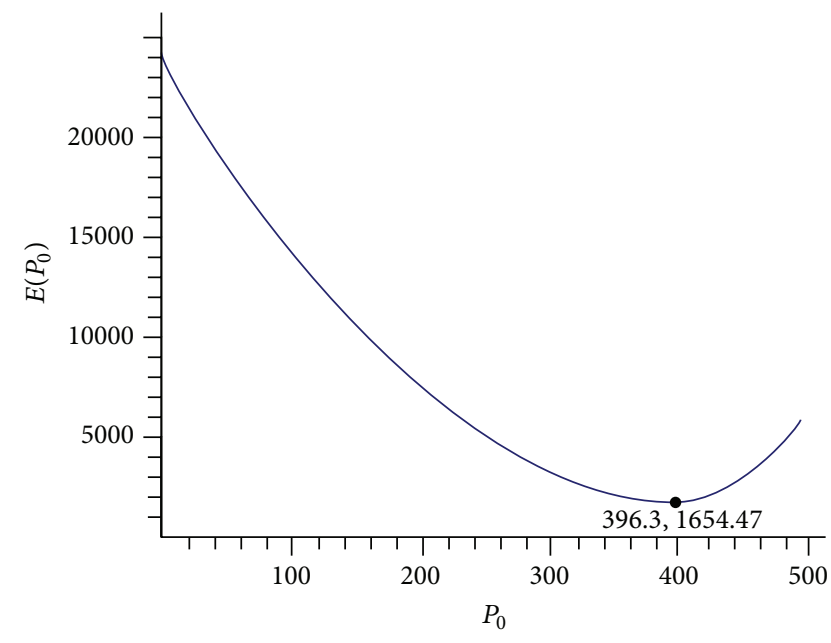

FIGURE 8: Energy consumptions distribution with probability load $P_{0}$ under $Q 3$.

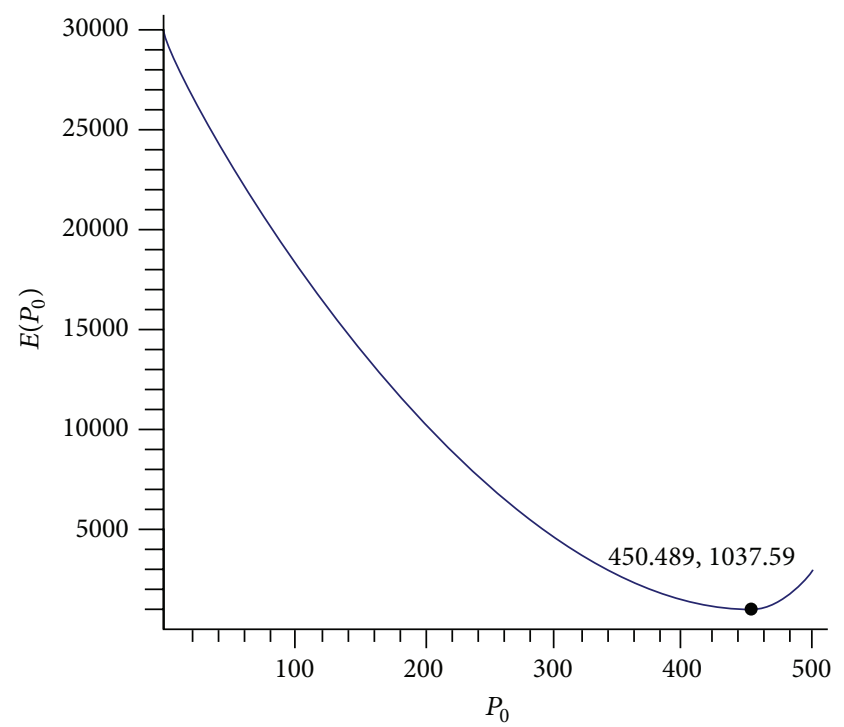

FIGURE 9: Energy consumptions distribution with probability load $P_{0}$ under $Q 4$.

TABLE 3: Ideal load $P_{0}$ corresponding to different load status levels.

\begin{tabular}{lc}
\hline Load status level & $P_{0}$ \\
\hline Q1 & $242 \mathrm{KN}$ \\
Q2 & $311 \mathrm{KN}$ \\
Q3 & $396 \mathrm{KN}$ \\
Q4 & $450 \mathrm{KN}$ \\
\hline
\end{tabular}

Through the above analysis, the ideal load $P_{0}$ corresponding to different load status levels can be initially determined as shown in Table 3.

When the load spectrum coefficient is unknown, the load can be considered to be conformed to $\left[0, P_{\max }\right]$ normal distribution. Then, the energy consumptions under the 


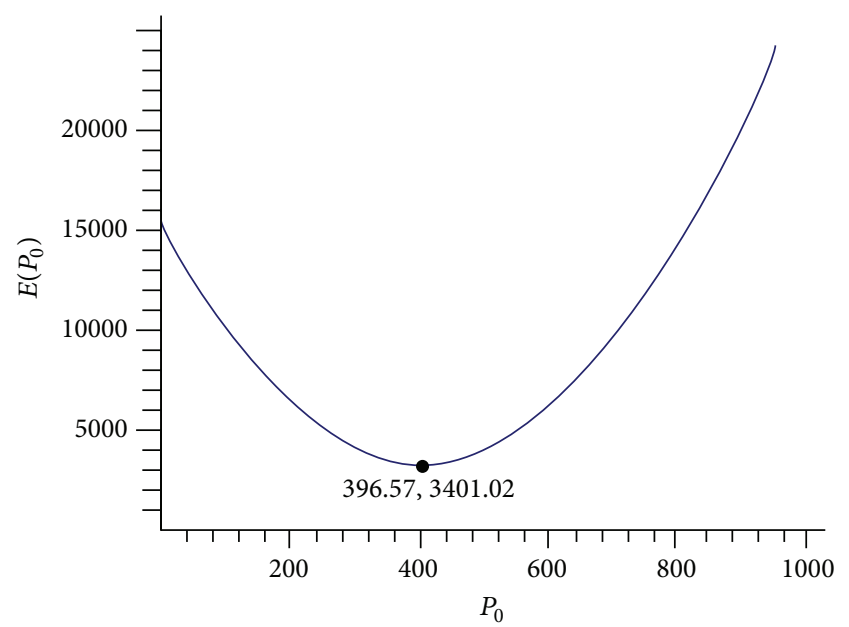

FIGURE 10: Energy consumptions distribution with probability load $P_{0}$ under $Q$.

uncertain load status level $Q$ can be obtained as well as energy consumptions distribution shown in Figure 10:

Q:

$$
\begin{aligned}
& E^{P_{0}}=0.00049 \cdot\left(\int_{0}^{P_{0}} e^{-(P-275)^{2} / 16200}(P+157)\left(P_{0}-P\right) d P\right. \\
& +\int_{P_{0}}^{500} e^{-(P-275)^{2} / 16200} \\
& \left.\times(P+157)\left(P-P_{0}\right) d P\right) \\
& =-775.587+27.4307 e^{\left(0.034-0.000062 P_{0}\right) P_{0}}+2.32 P_{0} \\
& +\left(12222.6-41.62 P_{0}\right) \operatorname{Erf}\left(2.166-0.006 P_{0}\right) \text {. }
\end{aligned}
$$

From Figure 10, energy consumption distribution law can be found when load spectrum coefficient is uncertain. When $P_{0}=0$, that is, without camber, energy consumptions are greatly much. With $P_{0}$ acting on the girder and increasing, $E^{P_{0}}$ decreases. When $P_{0}$ approaches $396.57 \mathrm{KN}$, the minimum of $E^{P_{0}}$ occurs as 3401.02 J. If $P_{0}$ continues to increase, $E^{P_{0}}$ will increase.

Different $P_{0}$ determines the corresponding reasonable camber to obtain the least energy consumption for climbing. According to formula (9) and $\alpha_{\text {camber }}+\alpha=0$, then

$$
\alpha_{\text {camber }}=-\alpha=\frac{P S^{2}}{3 E I} \frac{X}{S}\left(1-\frac{X}{S}\right)\left(1-\frac{2 X}{S}\right) .
$$

Because $\alpha_{\text {camber }}$ is very small,

$$
\begin{aligned}
& \frac{d y_{\text {camber }}}{d x}=\operatorname{tg} \alpha_{\text {camber }} \approx \alpha_{\text {camber }} \\
& d y_{\text {camber }}=\left[\frac{P S^{2}}{3 E I} \frac{X}{S}\left(1-\frac{X}{S}\right)\left(1-\frac{2 X}{S}\right)\right] d x .
\end{aligned}
$$

After integral solution of formula (21), the camber curve can be expressed as

$$
y_{\text {camber }}=\frac{P S^{3}}{6 E I}\left(\frac{X}{S}\right)^{2}\left(1-\frac{X}{S}\right)^{2} .
$$

Combined with the weight of the trolley $P_{\text {trolley }}$, the camber curve can be obtained and expressed as

$$
y_{\text {camber }}=\frac{\left(P_{0}+P_{\text {trolley }}\right) S^{3}}{6 E I}\left(\frac{X}{S}\right)^{2}\left(1-\frac{X}{S}\right)^{2} .
$$

\section{Conclusions}

Just as expressed in formula (23), the camber curve can be designed. However, in previous researches on camber design, $P_{0}$ is designed as fixed or rated loads. In fact, the hoisting weight of overhead crane is not fixed, and energy consumptions under certain camber with different hoisting/load will vary. Camber design based on the fixed or rated load may not get the optimal energy-saving. This research seeks to get ideal $P_{0}$ for trolley moving with probabilistic loads to obtain the least energy consumption. Then, according to formula (23), energy-saving camber design of overhead travelling crane can be obtained. Besides, some conclusions can be drawn as below.

(1) With the load status level improved, the hoisting/load mean gradually increases and the load distribution becomes more concentrated. The loads of Q4 are distributed around the rated load with a certain probability of overloading.

(2) The minimum energy consumptions occur when $P$ approaches $P_{0}$ and the energy consumptions are less when $P<P_{0}$ than when $P>P_{0}$ because of heavier loading. So, heavier load can be considered for camber design to guarantee less energy consumptions when overloading.

The research results of this paper can also provide a great reference value to cutting girder web along a certain curve for prefabrication.

\section{Conflict of Interests}

The authors declare that there is no conflict of interests regarding the publication of this paper.

\section{Acknowledgments}

This work was financially supported by National Foundation of General Administration of Quality Supervision and Inspection (2012QK178), Program of Science Foundation of General Administration of Quality Supervision and Inspection of Jiangsu Province (KJ103708), and "excellence planszijin star" Foundation of Nanjing University of Science. Also, the work is preresearch of the National Natural Science Foundation of China (research on energy consumption modelling and methodology of energy-saving design for cranes). The supports are gratefully acknowledged. 


\section{References}

[1] P. R. Patel and V. K. Patel, "A review on structural analysis of overhead crane girder using FEA technique," International Journal of Engineering Science and Innovative Technology, vol. 2, no. 4, pp. 41-44, 2013.

[2] T. Yifei, Y. Wei, Y. Zhen, L. Dongbo, and L. Xiangdong, "Research on multidisciplinary optimization design of bridge crane," Mathematical Problems in Engineering, vol. 2013, Article ID 763545, 10 pages, 2013.

[3] S. G. Lee and N. Q. Hoang, "Energy-based approach for controller design of overhead cranes: a comparative study," Applied Mechanics and Materials, vol. 365-366, pp. 784-787, 2010.

[4] C. Li-Feng, "Methods and analysis of bridge camber and deformation of main girder in gantry crane," Equipment Manufacturing Technology, no. 5, pp. 124-125, 2010.

[5] C. R. Bradlee, "Method of measuring camber," Us Patent 4,794,773, 1989.

[6] F. Rongbo, "Camber \& pre arch curve of cranes," Hoisting and Conveying Machinery, vol. 2, pp. 16-18, 1990.

[7] G. Shen, X. Li, D. Li, and C. Zhou, "Reaseach on energy-saving design of arch curve of bridge crane girder," in Proceedings of the International Conference on Remote Sensing, Environment and Transportation Engineering (RSETE '11), pp. 1448-1450, Nanjing, China, June 2011.

[8] T. Jiantao, Load Statistical Analisys and Reliable Indicator Research of Bridge Crane, Taiyuan University of Science and Technology, Taiyuan, China, 2011.

[9] S. Živanović, R. P. Johnson, H. V. Dang, and J. Dobric, "Design and construction of a very lively bridge," in Topics in Dynamics of Civil Structures, vol. 4, pp. 371-380, 2013.

[10] X. Gelin, GB/T3811-2008 Design Rules for Cranes, Chinese Standard Press, Beijing, China, 2008. 


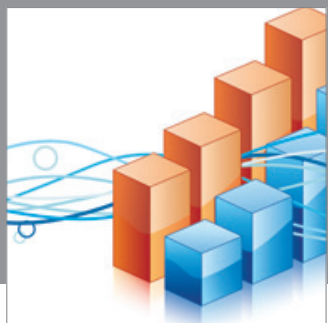

Advances in

Operations Research

mansans

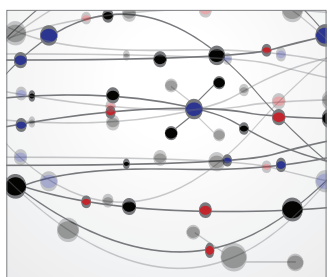

The Scientific World Journal
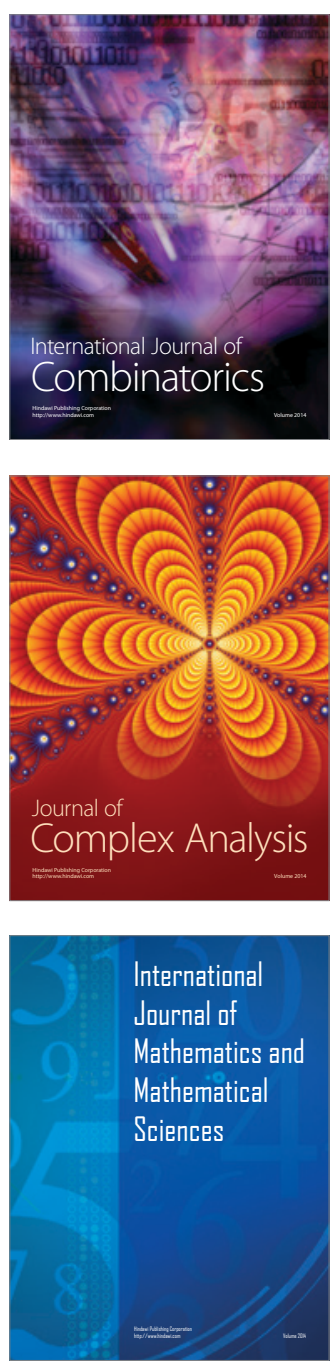
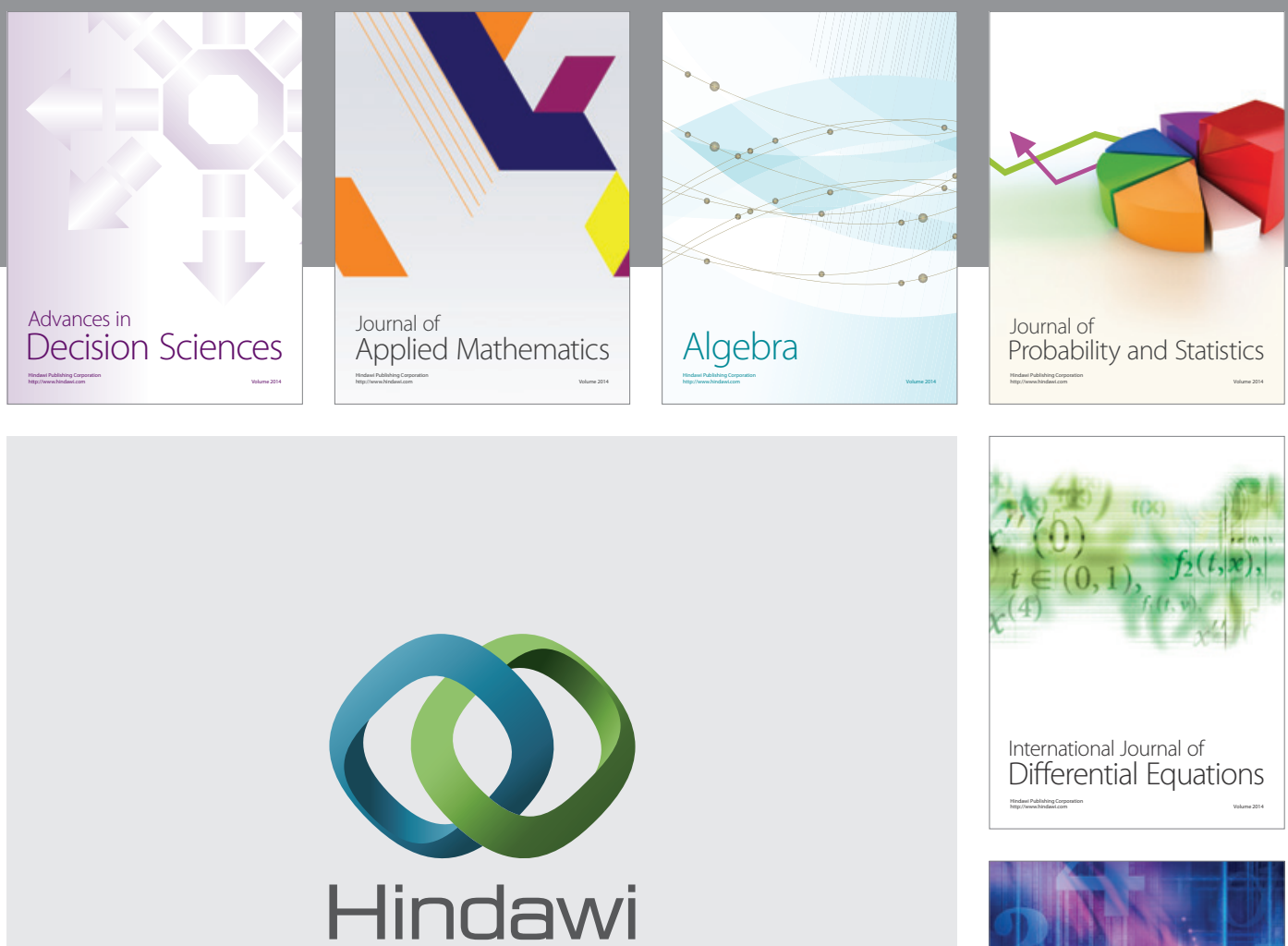

Submit your manuscripts at http://www.hindawi.com
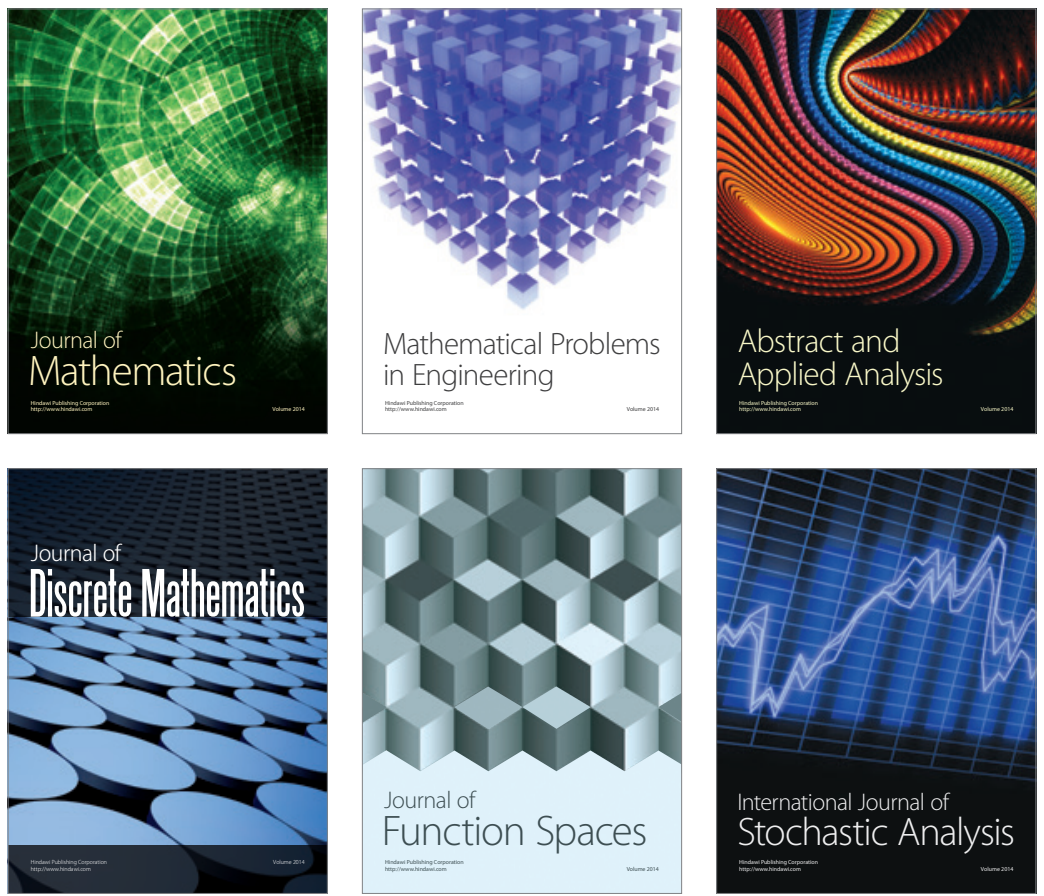

Journal of

Function Spaces

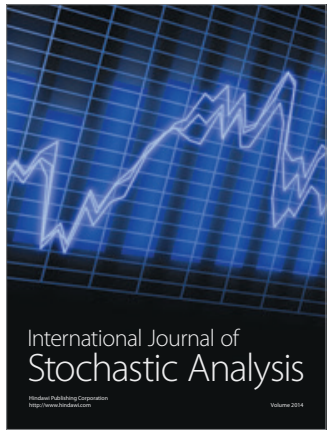

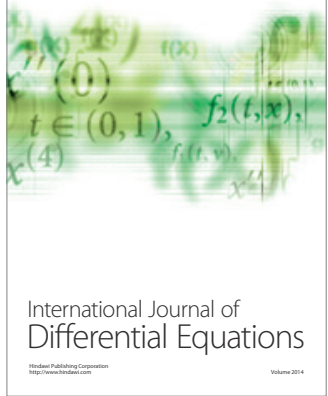
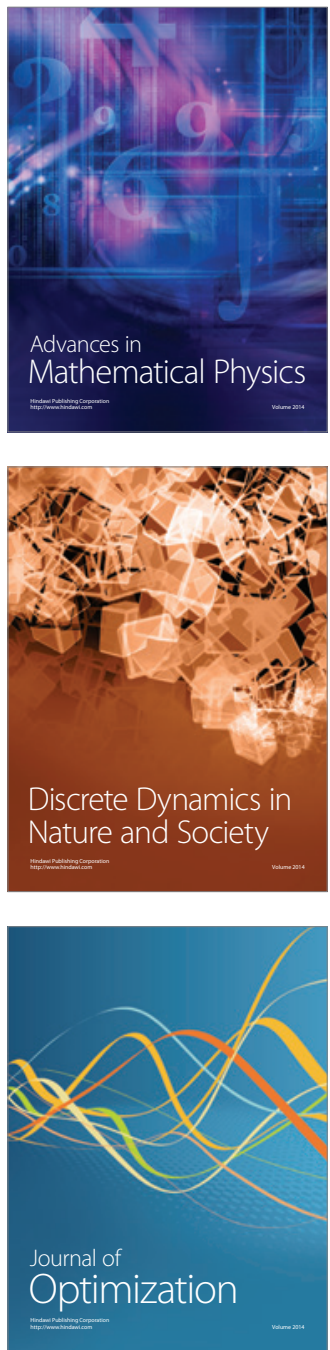